\title{
Contingent valuation: confusions, problems, and solutions
}

\section{Other Journal Item}

\section{Author(s):}

Schläpfer, Felix

Publication date:

2009-04-15

Permanent link:

https://doi.org/10.3929/ethz-a-005774600

Rights / license:

In Copyright - Non-Commercial Use Permitted

Originally published in:

Ecological Economics 68(6), https://doi.org/10.1016/j.ecolecon.2009.01.014 


\title{
Ecological Economics, in press
}

Section: News and Views

Editor: Richard B. Howarth

\section{Eliciting the preferences of "rational fools"?}

\author{
Felix Schläpfer
}

Environmental Policy and Economics, Institute for Environmental Decisions, ETH Zurich, 8092 Zurich, Switzerland, Tel.: +41 44632 8508, E-mail: felix.schlaepfer@env.ethz.ch.

14 January, 2009

Many ecological and environmental economists are beginning to understand that the problems with the existing paradigm in contingent valuation are more fundamental than the rhetoric in the most authoritative writings on the topic suggest. Nevertheless, articles that address these problems openly remain rare in important journals that are defining the field. Authors seem to fear that their articles would be rejected by reviewers and editors who had ignored those same problems in previous research. But how should we hope to bring the field ahead if we do not feel free to talk about the fundamental problems of the "state of the art"?

The aim of this commentary is to help foster this debate. I try to formulate more clearly than before what I perceive to be the fundamental problems of the existing paradigm. I will then argue that a closer look at economic theory, innovative research on environmental 
valuation, and recent positive research on how people make choices in the political domain provide solutions to these problems. Together, these solutions amount to a new survey paradigm which, unlike the "state of the art”, is compatible with the larger bodies of related work in economics, psychology, and political science.

The broader debate in Ecological Economics about whether cost-benefit analysis based on individual preferences is an appropriate paradigm in the public sector is beyond the scope of this comment. I assume that, for now, the aim of improving stated preference methods is accepted.

\section{Three confusions}

The "state of the art" in contingent valuation (including "choice experiments") is based on three fundamental confusions in the literature.

Problem \#1: "Referendum” contingent valuation is not incentive compatible. Contrary claims (e.g. Mitchell and Carson, 1989; Arrow et al., 1993; Hanemann, 1994) seem to be based on a misunderstanding of the Gibbard-Satterthwaite Theorem (Gibbard, 1973; Satterthwaite, 1975). They seem to be the result of a confusion of questions involving actual prices (to which the Theorem relates) and hypothetical prices (as used in contingent valuation; see e.g. Flores and Strong, 2007). The consequences are easy to show in an example. On a question "Would you be willing to pay \$1000 in income taxes to establish a new national park in the US?”, a green activist (with a willingness somewhere between $\$ 1$ and $\$ 500$ and an expected tax increase of perhaps $\$ 1$ due to the project) may easily provide a strategic “yes” in order to promote the funding of the park. Due to the confusion of incentive theory, researchers failed to recognize the importance of asking questions involving credible prices and policy propositions (see Flores and Strong 2007). 
Problem \#2: Individuals do not know their preferences for complex public goods.

Contrary claims are based on a confusion of different rationality concepts. For instance, Hanemann (1994, p. 29) argues: “Many analysts see a substantial core of rationality in voter behaviour.” The same argument in defense of stated preferences is made by Carson et al. (2001). These authors confuse as-if rationality (Friedman, 1953) ${ }^{1}$ based on political advice (Lupia 1994), which is sufficient for consistent voting in a competitive political information environment, with literal rationality, which would be necessary for consistent responses in a self-contained survey. Not surprisingly then, framing and anchoring experiments - in line with verbal protocol analysis (Schkade and Payne, 1994, Clark et al., 2000) - show that survey responses about unfamiliar goods are attitude expressions on scales largely determined by framing (e.g. Tversky and Kahneman, 1981; Kahneman and Knetsch, 1992; Kahneman et al., 1999; Ariely et al., 2003).

Problem \#3: Survey researchers are information monopolists. Given that framing matters and that the survey researcher has the power to frame specific questions that have never been publicly discussed, he can manipulate the outcome through providing “appropriate” subsets of potentially relevant information. When Hanemann (1994, p. 28) argues: "If a subjects responds thoughtfully to a question about voting to raise taxes for a public good, by what criterion is that not a valid preference?”, he essentially confuses competitive and "dictatorial” information environments. He neglects that the legitimacy of voting hinges on preference formation in a competitive political information environment (e.g. Downs, 1957; Druckman, 2001; Druckman, 2004; Lupia and Matsusaka, 2004).

Reviewers of several journals have been reluctant to pass articles that expose these confusions. One high profile example is the JEEM paper by Kahneman and Knetsch (1992). ${ }^{2}$ This paper appeared simultaneously with a criticism already. A second criticism was also

\footnotetext{
${ }^{1}$ Friedman's example is expert billiard players who behave as if they knew the laws of physics.

${ }^{2}$ I am grateful to a reviewer for pointing out this example.
} 
published later and the authors were not allowed to reply to this, despite their protests (see Spash 2008a, p.431). A more recent example is a paper by Flores and Strong (2007) who break a taboo by showing what happens when respondents do not believe the costs presented in single-shot dichotomous-choice questions (see Champ et al. 2002). The reviewers of two environmental economics journals rejected the paper (Nicholas Flores, personal communication), although the authors provide the key for solving the incentive problem in economic preference elicitation. By contrast, when papers cover up and propagate these confusions this seems to often escape the attention of the reviewers. Examples are Vossler and Kerkvliet (2003) who wilfully confuse stated preference surveys and pre-election polls to conclude that stated preference surveys predict votes, or Carson and Groves (2007) who blur the incentive issue by presenting a typology of elicitation formats that precisely omits those non-incentive-compatible formats that are now standard in stated preference research. Both of these papers are now widely cited.

\section{Three solutions}

Identifying and formulating the confusions in the literature is the basis for finding solutions. Recent critical research in environmental valuation, psychology, and political science offer the insights on which an alternative paradigm in preference elicitation may be built. The key insights from this literature are that preferences in the political domain are typically formed (i) about credible alternatives (notably including credible prices), (ii) in a social context (rather than individually), and (iii) based on competing information (rather than under information monopoly conditions).

What emerges from the combination of these insights is an alternative survey paradigm which, unlike the existing paradigm, is responsive to large bodies of related work on bounded rationality, constructed preferences, simplified heuristics, on the role of 
institutions in decision making, information cost, and asymmetric information. The three needed amendments to the NOAA recommendations (Arrow et al., 1993) are:

Solution \#1: Keep the hypothetical costs of the (realistic) policy scenario within a range that is credible to the respondents. When true (or at least credible) expected costs are presented in a single dichotomous choice questions, then the alternatives are well defined, and it is not possible to make a gain from answering strategically (Gibbard, 1973; Satterthwaite, 1975; Green et al., 1998; Flores and Strong, 2007).

Solution \#2: Offer opportunities for communication with peers and experts. This context helps the respondents to better understand the consequences of the alternatives (e.g. Fishkin, 1995; Sagoff, 1998; Payne et al., 1999; Macmillan et al., 2002; Vatn, 2004, Howarth and Wilson, 2006; Alvarez-Farizo et al., 2006; Spash, 2007, 2008b).

Solution \#3. Offer access to credible advice generated through open political competition among familiar parties with known interests and values. Political scientists have shown that even voters with relatively low levels of factual knowledge are in such information environments able to cast votes in line with their interests and values (e.g. Lupia, 1994; Lupia and Matsusaka, 2004). The institutional context breaks up the survey researcher’s (or any hand-selected experts') information monopoly and power to frame (Druckman, 2001; Druckman, 2004; Schläpfer, et al., 2008; Schläpfer, 2008).

\section{Conclusions}

The amended survey paradigm eliminates strategic opportunities by asking credible questions, and it uses a principled way to provide "adequate” information. Remarkably, in light of its origin in political science, and "heterodox" approaches in environmental valuation, the behavioral assumptions of the paradigm are no different from those implicit in classic studies of voting (e.g. Downs ,1957; Deacon and Shapiro, 1975; Kahn and Matsusaka, 1997) which 
had always been acceptable in environmental economics journals. Why then are some journals so resistant to these insights and innovations?

It seems that many researchers have been trapped in a prisoner's dilemma. Proponents of the existing paradigm who wilfully propagate the old confusions (or are reluctant to correct them) dominate research in the field. From the perspective of the individual researcher, the best strategy seems to be to keep submitting and accepting papers that are based on the same confusions - papers that distinguish themselves from "heterodox" approaches by taking respondents to be unboundedly rational in information processing while fools in the face of opportunities for answering strategically.

One way out of prisoner's dilemmas is communication. Let's talk openly about the confusions and contradictions! A second way out is to gradually change the norms and incentives in publishing. As in other fields of science, stated preference research should be required to respond to known problems. Journal Editors may have a responsibility to make the first steps. Until these norms are clearly changing, we are fortunate to have Ecological Economics where the "rational fool" is not the only acceptable behavioral model in preference elicitation.

\section{Acknowledgements}

I am grateful for discussions with many colleagues in the field and for the detailed comments provided by one reviewer and the Editor on a previous version of the manuscript.

\section{References}

Alvarez-Farizo, B. and Hanley, N., 2006. Improving the process of valuing non-market benefits: combining citizens' juries with choice modelling. Land Econ., 82:465-478. 
Ariely, D., Loewenstein, G. and Prelec, D., 2003. "Coherent arbitraryness": stable demand curves without stable preferences. Quarterly J. of Econ., 118:73-105.

Arrow, K., Solow, R., Portney, P.R., Leamer, E.E., Radner, R., Schuman, H. and Solow, R., 1993. Report of the NOAA Panel on contingent valuation. Federal Register, 58:46014644.

Carson, R.T. and Groves, T., 2007. Incentive and informational properties of preference questions. Env. Res. Econ., 37:181-210.

Carson, R.T., Flores, N.E. and Meade, N.F., 2001. Contingent valuation: Controversies and evidence. Env. Res. Econ., 19:173-210.

Champ, P.A., Flores, N.E., Brown, T.C. and Chivers, J., 2002. Contingent valuation and incentives. Land Econ., 78: 591-604.

Clark, J., Burgess, J. and Harrison, C.M., 2000. "I struggled with this money business": respondents' perspectives on contingent valuation. Ecol. Econ., 33:45-62.

Deacon, R. and Shapiro, P., 1975. Private preference for collective goods revealed through voting on referenda. Amer. Econ. Rev., 65:943-955.

Downs, A., 1957, An Economic Theory of Democracy. Harper and Row, New York.

Druckman, J.N., 2001. The implications of framing effects for citizen competence. Political Behavior, 23:225-256.

Druckman, J.N., 2004. Political preference formation: competition, deliberation and the (ir)relevance of framing effects. Amer. Pol. Sci. Rev., 98:671-686.

Fishkin, J.S., 1995. The Voice of the People: Public Opinion and Democracy. Yale University Press, New Haven, CT.

Flores, N.E. and Strong, A., 2007. Cost credibility and the stated preference analysis of public goods. Res. Energy Econ., 29:195-205.

Friedman, M., 1953. The Methodology of Positive Economics. Essays in Positive Economics. University of Chicago Press, Chicago. 
Gibbard, A., 1973. Manipulation of Voting Schemes - General Result. Econometrica, 41:587601.

Green, D., Jacowitz, K.E., Kahneman, D. and McFadden, D., 1998. Referendum contingent valuation, anchoring, and willingness to pay for public goods. Res. Energy Econ., 20:85-116.

Hanemann, W.M., 1994. Valuing the environment through contingent valuation. J. Econ. Perspectives, 8:19-43.

Howarth, R.B. and Wilson, M.A., 2006. A theoretical approach to deliberative valuation: Aggregation by mutual consent. Land Econ., 82:1-16.

Kahn, M.E. and Matsusaka, J. G., 1997. Demand for environmental goods: Evidence from voting patterns on California initiatives. Journal of Law \& Economics, 40:137-173.

Kahneman, D. and Knetsch, J.L., 1992. Valuing public goods - the purchase of moral satisfaction. J. Env. Econ. Mgt., 22:57-70.

Kahneman, D. and Tversky, A., 1984. Choices, values, and frames. American Psychologist, 39:341-350.

Kahneman, D., Ritov, I. and Schkade, D. A., 1999. Economic preferences or attitude expressions?: an analysis of dollar responses to public issues. J. Risk and Uncertainty, 19:203-235.

Kotchen, M.J. and Powers, S.M., 2006. Explaining the appearance and success of voter referenda for open-space conservation. J. Env. Econ. Mgt., 52:373-390.

Lupia, A. and Matsusaka, J.G., 2004. Direct democracy: new approaches to old questions. Ann. Rev. Pol. Sci., 7:463-482.

Lupia, A., 1994. Shortcuts versus encyclopedias - information and voting behavior in California insurance reform elections. Amer. Pol. Sci. Rev., 88:63-76. 
Macmillan, D.C., Philip, L., Hanley, N. and Alvarez-Farizo, B., 2002. Valuing the non-market benefits of wild goose conservation: a comparison of interview and group-based approaches. Ecol. Econ., 43:49-59.

Mitchell, R.C. and Carson, R.T., 1989, Using Surveys to Value Public Goods: The Contingent Valuation Method. Resources for the Future, Washington, D. C.

Payne, J.W., Bettman, J.R. and Schkade, D.A., 1999. Measuring constructed preferences: towards a building code. J. Risk and Uncertainty, 19:243-270.

Sagoff, M., 1998. Aggregation and deliberation in valuing environmental public goods: A look beyond contingent pricing. Ecol. Econ., 24:213-230.

Satterthwaite, M.A., 1975. Strategy-proofness and Arrows conditions - existence and correspondence theorems for voting procedures and social welfare functions. J. Econ. Theory, 10:187-217.

Schkade, D.A. and Payne, J.W., 1994. How people respond to contingent valuation questions - a cerbal protocol analysis of willingness-to-pay for an environmental regulation. J. Env. Econ. Mgt., 26:88-109.

Schläpfer, F., 2008. Contingent valuation: a new perspective. Ecol. Econ., 64, 729-740.

Schläpfer, F., Schmitt, M. and Roschewitz, A., 2008. Competitive politics, simplified heuristics, and preferences for public goods. Ecol. Econ., 65:574-589.

Spash, C.L., 2008a. Contingent valuation as a research method: environmental values and human behaviour. In: A. Lewis (Editor), The Cambridge Handbook of Psychology and Economic Behaviour. Cambridge University Press, Cambridge: pp. 429-453.

Spash, C.L., 2008b. Deliberative monetary valuation and the evidence for a new value theory. Land Econ., 84:469-488.

Spash, C.L., 2007. Deliberative monetary valuation (DMV): Issues in combining economic and political processes to value environmental change. Ecol. Econ. 63:690-699. 
Tversky, A. and Kahneman, D., 1981. The framing of decisions and the psychology of choice. Science, 211:453-458.

Vatn, A., 2004. Environmental valuation and rationality. Land Econ., 80:1-18.

Vossler, C. A. and Kerkvliet, J., 2003. A criterion validity test of the contingent valuation method: comparing hypothetical and actual voting behavior for a public referendum. J. Env. Econ. Mgt., 45:631-649. 